\title{
Corosolic acid inhibits the proliferation of osteosarcoma cells by inducing apoptosis
}

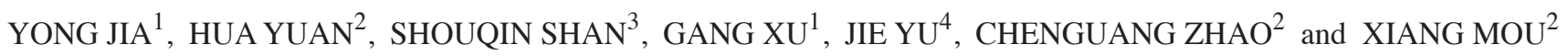 \\ ${ }^{1}$ Orthopedic Center of Chinese PLA, Urumqi General Hospital of Lanzhou Military Region, Urumqi, Xinjiang 830000; \\ ${ }^{2}$ Department of Rehabilitation, Xijing Hospital, Fourth Military Medical University, Xi'an, Shaanxi 710032; \\ ${ }^{3}$ Department of Rehabilitation, Qingdao First Sanatorium of Jinan Military Region, Qingdao, Shandong 266071; \\ ${ }^{4}$ Department of Information, Urumqi General Hospital of Lanzhou Military Region, Urumqi, Xinjiang 830000, P.R. China
}

Received June 18, 2015; Accepted August 25, 2016

DOI: $10.3892 / 01.2016 .5185$

\begin{abstract}
Corosolic acid (CRA), a pentacyclic triterpene isolated from medicinal herbs, has been reported to exhibit anticancer properties in several cancers. However, the anticancer activity of CRA in osteosarcoma cells is still unclear. In the present study, the inhibitory effect of CRA in osteosarcoma MG-63 cells was investigated, and the results revealed that CRA significantly inhibited the viability of MG-63 cells in a dose- and time-dependent manner. A typical apoptotic hallmark such as DNA ladder was detected by agarose gel electrophoresis following treatment with CRA. Further experiments demonstrated that CRA induced apoptosis of MG-63 cells by flow cytometry using propidium iodide and annexin $\mathrm{V}$ staining. In addition, it was observed that the apoptosis of MG-63 cells induced by CRA was closely associated with activation of caspase- 3 and caspase-9, loss of mitochondrial membrane potential, and release of cytochrome $c$ from mitochondria, suggesting that CRA may trigger the activation of the mitochondria-mediated apoptosis pathway. In addition, the inhibition of caspase activity attenuated the CRA-induced apoptosis of MG-63 cells, which further confirmed the role of the mitochondrial pathway in CRA-induced apoptosis. These results indicated that CRA could induce the apoptosis of osteosarcoma cells through activating the mitochondrial pathway, which provides an evidence that CRA may be a useful chemotherapeutic agent for osteosarcoma.
\end{abstract}

Correspondence to: Professor Chenguang Zhao or Professor Xiang Mou, Department of Rehabilitation, Xijing Hospital, Fourth Military Medical University, 15 Changle West Road, Xi'an, Shaanxi 710032, P.R. China

E-mail: zhaocg001@163.com

E-mail: moux237@126.com

Key words: CRA, osteosarcoma, apoptosis, mitochondrial pathway

\section{Introduction}

Corosolic acid (CRA), a triterpenoid named $2 \alpha$-hydroxyursolic acid, is a natural compound derived from traditional Chinese medicinal herbs (1). CRA exists in various plants, including Schisandra chinensis (2), Lagerstroemia speciosa (3), Orthosiphon stamineus (4) and Eriobotrya japonica (5). CRA has been reported to possess numerous biological activities, including anti-diabetic $(4,5)$, antioxidant (6), anti-atherosclerotic (7), cholesterol-reducing (8) and anti-inflammatory (9), which suggested the potential therapeutic value of CRA. Previous studies have reported that CRA could suppresses the growth of various types of tumors, including glioblastoma (10), leukemia (11), gastric cancer (12) and lung cancer (1). However, the effect of CRA on osteosarcoma remains unclear.

Osteosarcoma is the most common malignant primary bone tumor that occurs in children and adolescents, which comprises $20 \%$ of all bone tumors and $\sim 5 \%$ of all pediatric tumors (13). The highest incidence of osteosarcoma appears in the second decade of life, implying an association between bone growth and tumor development (14). In recent years, due to multimodal therapeutic approaches combining high-dose chemotherapy, significant improvements in patient survival rates have been achieved (15). However, the overall relapse free-survival rate over 5 years has stagnated at $65-75 \%$ (16), being distant metastases the leading cause of mortality in osteosarcoma patients (17). Since chemotherapy is still the major therapeutic option for osteosarcoma, the exploration and development of more effective therapeutic agents is required.

Apoptosis, the major form of cell suicide, is critical to various physiological processes and to the maintenance of homeostasis in multicellular organisms (18). It is clear that apoptosis is critical for the cytotoxicity induced by anticancer drugs (19). Over the years, accumulating evidence has clearly indicated that anticancer drugs are able to induce apoptosis, and that this process is involved in the mediation of their cytotoxic effects (20). In addition, the selective regulation of the apoptotic pathway in cancer cells has been the goal of cancer researchers (21). However, the effect of CRA on the apoptosis of osteosarcoma cells remains unknown. 
In the present study, the effects of CRA on the cell proliferation and tumor growth of osteosarcoma were assessed in vitro, and the impact of CRA on the apoptosis of osteosarcoma cells was investigated. The present study demonstrated that CRA treatment resulted in a significant inhibition of cell proliferation and tumor growth of osteosarcoma, which was closely associated with the cell apoptosis induced by CRA through the mitochondrial pathway. Therefore, our results not only provide a potential chemotherapeutic agent for osteosarcoma, but also an insight into the mechanism underlying the anticancer efficacy of CRA.

\section{Materials and methods}

Antibodies and reagents. Primary antibodies specific for cytochrome $c$ (sc-8385), complex (COX) IV (sc-69359) and $\beta$-actin (sc-47778) were purchased from Santa Cruz Biotechnology, Inc. (Santa Cruz, CA, USA). Secondary antibodies were purchased from Cell Signaling Technology, Inc. (Beverly, MA, USA). 3-(4,5-Dimethyl-2-yl)-2,5-diphenyl tetrazolium bromide (MTT) and propidium iodide (PI) were obtained from Sigma-Aldrich (Merck Millipore, Darmstadt, Germany). The Annexin V-FITC Apoptosis Detection kit was purchased from BD Pharmingen ${ }^{\mathrm{TM}}$ (BD Biosciences, Franklin Lakes, NJ, USA). The Caspase-3 Activity Assay kit and the Caspase-9 Activity Assay kit were purchased from NanJing KeyGen Biotech Co., Ltd. (Nanjing, China). CRA was purchased from Jianfeng Natural Product R\&D Co., Ltd. (Tianjin, China).

Cells and culture conditions. Human osteosarcoma cells MG-63 were obtained from the American Type Culture Collection (Rockville, MD, USA) and cultured in Dulbecco's modified Eagle's medium (Sigma-Aldrich; Merck Millipore) supplemented with $10 \%$ heat-inactivated fetal bovine serum (HyClone; GE Healthcare Life Sciences, Logan, UT, USA), $100 \mathrm{mg} / \mathrm{ml}$ penicillin and $100 \mathrm{mg} / \mathrm{ml}$ streptomycin (Invitrogen; Thermo Fisher Scientific, Inc., Waltham, MA, USA) in a humidified incubator at $37^{\circ} \mathrm{C}$ in a $5 \% \mathrm{CO}_{2}$ atmosphere. CRA was dissolved in $100 \mu \mathrm{l}$ dimethylsulfoxide (DMSO) prior to addition to the medium. The maximum concentration of DMSO in the medium did not exceed $0.1 \%$ (v/v). Cells treated with DMSO only served as a vehicle control.

Cell viability assay. Cell viability was detected by MTT assay as described previously (22). Briefly, cells were seeded in 96-well culture plates at a density of $1 \times 10^{4}$ cells/well and incubated for $12 \mathrm{~h}$ at $37^{\circ} \mathrm{C}$. Then, cells were treated with several concentrations of CRA and further incubated for 12 , 24, 36 and $48 \mathrm{~h}$. Finally, MTT was added to each well and incubated for $4 \mathrm{~h}$ at $37^{\circ} \mathrm{C}$. The resulting formazan product was then dissolved in $100 \mu \mathrm{l}$ DMSO, and the absorbance was determined at $540 \mathrm{~nm}$ using a Bio-Rad 3350 microplate reader (Bio-Rad Laboratories, Inc., Hercules, CA, USA).

Detection of apoptosis. Once the cells were harvested, double staining with annexin $\mathrm{V}$ and PI was conducted using the BD Pharmingen $^{\mathrm{TM}}$ Annexin V-FITC Apoptosis Detection kit according to the manufacturer's protocol. Then, the stained cells were detected using a FACSCalibur flow cytometer (BD Biosciences, San Jose, CA, USA).
DNA gel electrophoresis. DNA was isolated from MG-63 cells treated with CRA according to the method described by Ariffin et al (23). DNA samples were subjected to electrophoresis in a $1 \%(\mathrm{w} / \mathrm{v})$ agarose gel for $1 \mathrm{~h}$ at $100 \mathrm{~V}$. The gel was examined under ultraviolet transillumination following ethidium bromide staining to determine the extent of apoptotic DNA fragmentation.

Detection of caspase-3 and -9 activities. The activities of caspase-3 and -9 in cell lysates were determined using a colorimetric assay kit according to the manufacturer's protocol. Briefly, the cells were harvested in cell lysis buffer (NanJing KeyGen Biotech Co., Ltd.), and cell lysates were prepared following the manufacturer's protocol. The protein concentrations were determined using the BCA Protein Assay reagent (Pierce Biotechnology, Inc., Rockford, IL, USA). Samples of the cell lysates (100 $\mu \mathrm{g}$ protein/sample) were mixed with reaction buffer and substrate, and incubated for $4 \mathrm{~h}$ at $37^{\circ} \mathrm{C}$ in the dark. The absorbance was measured at $405 \mathrm{~nm}$, and the sample readings were calculated by subtracting the absorbance of the blank samples.

Measurement of mitochondrial membrane potential. The change in mitochondrial membrane potential in osteosarcoma cells following exposure to CRA was measured by flow cytometry using the fluorescent lipophilic cationic probe 5,5',6,6'-tetrachloro-1,1',3,3'-tetraethylbenzimidazolcarbo-

cyanine iodide (JC-1) as described previously (24). JC-1 accumulates selectively within normal mitochondria to form multimer J-aggregates emitting red fluorescence (25). If the mitochondrial membrane potential is altered, JC-1 can not aggregate in the mitochondria and remains in the cytoplasm in its monomeric form emitting green fluorescence (26). Thus, the color of the dye changes from orange to green depending on the mitochondrial membrane potential, and can be analyzed by fluorescence-activated cell sorting (FACS) with green fluorescence in channel 1 and orange emission in channel 2.

Preparation of mitochondrial and cytosolic fractions. The extraction of the mitochondrial and cytosolic fractions was performed using a Mitochondria/Cytosol Fractionation kit (Abcam, Cambridge, MA, USA). Cells exposed to CRA at the concentrations indicated were harvested and washed with ice-cold phosphate-buffered saline (PBS) twice, and then the cells were resuspended in cytosol extraction buffer. Upon incubation on ice, the cells were homogenized, and the homogenates were centrifuged at $700 \times \mathrm{g}$ for $10 \mathrm{~min}$ at $4^{\circ} \mathrm{C}$. The supernatants were further centrifuged at $10,000 \times g$ for $30 \mathrm{~min}$ at $4^{\circ} \mathrm{C}$ to separate the cytosolic fraction. Then, the pellet, which represented the mitochondrial fraction, was resuspended in mitochondrial extraction buffer. All the fractions were stored at $-80^{\circ} \mathrm{C}$ for further detection.

Western blotting. Following treatment of MG-63 cells with CRA, the cells were harvested, washed with cold PBS and lysed with ice-cold lysis buffer supplemented with protease inhibitors as detailed previously (27). For western blot analysis of cytochrome $c$ and COX IV, the mitochondrial and cytosolic fractions were prepared, respectively, and proteins were separated by $10 \%$ sodium dodecyl sulfate polyacrylamide 
gel electrophoresis and transferred onto polyvinylidene fluoride membranes. Upon blocking with $5 \%$ fat-free milk, the membrane was incubated with the corresponding primary antibody at $1: 300$ dilution at $4^{\circ} \mathrm{C}$ overnight. Upon washing, the membrane was incubated with the appropriate horseradish peroxidase-conjugated secondary antibody at 1:10,000 dilution for $1 \mathrm{~h}$ at room temperature, and the immunoreactive bands were visualized using enhanced chemiluminescence reagents (EMD Millipore, Billerica, MA, USA).

Statistical analysis. All experiments were performed in triplicate and repeated three times independently. The data were expressed as the mean \pm standard deviation. Statistical analysis was performed using Prism 5 software (GraphPad Software, Inc., La Jolla, CA, USA). One-way analysis of variance followed by Dunnett's test were performed, and $\mathrm{P}<0.05$ was considered to indicate a statistically significant difference.

\section{Results}

CRA inhibits osteosarcoma cell proliferation in vitro. To assess the effect of CRA on the proliferation of osteosarcoma cells, the viability of osteosarcoma cells treated with different concentrations of CRA (10-40 $\mu \mathrm{M})$ was detected using MTT assay. Osteosarcoma cells (MG-63) were cultured for 12, 24 and $48 \mathrm{~h}$. As shown in Fig. 1, the treatment of MG-63 cells with CRA resulted in a significant reduction in the viability of the cells in a dose-dependent manner $(\mathrm{P}<0.001)$. Treatment with CRA for $12 \mathrm{~h}$ did not result in a significant reduction in cell viability, whereas following treatment for 24 and $48 \mathrm{~h}$, a significant reduction in cell viability was observed. In addition, it was observed that the inhibitory effect of CRA was also time dependent. These results indicated that $\mathrm{CRA}$ effectively inhibited the viability of osteosarcoma cells, suggesting that CRA could inhibit the proliferation of osteosarcoma cells. Since a significant decrease in cell viability of MG-63 cells was observed after 24 h of CRA treatment, this time point was selected for further studies.

CRA induces apoptosis in osteosarcoma cells. To determine whether CRA induced the apoptosis of osteosarcoma cells, the change in DNA of MG-63 cells following CRA treatment was measured using a DNA ladder assay (Fig. 2A). Once MG-63 cells were treated with the indicated concentrations of CRA for $24 \mathrm{~h}$, DNA was extracted. Via agarose gel electrophoresis, an obvious DNA ladder, a classic indicator of apoptotic changes (28), was detected in MG-63 cells treated with CRA (20, 30 and $40 \mu \mathrm{M})$, suggesting that CRA treatment may induce apoptosis in osteosarcoma cells.

To further verify the observation of apoptosis in MG-63 cells, cells treated with CRA were analyzed by flow cytometry. In this assay, cells were stained with annexin $\mathrm{V}$ conjugated with fluorescein isothiocyanate (FITC) and PI. The cells in the lower right (LR) quadrant of the histogram in Fig. 2B represent the number of early apoptotic cells, and those in the upper right quadrant represented the cells in late apoptosis, which have taken up both FITC and PI (29). It was observed that treatment with CRA for $24 \mathrm{~h}$ significantly increased the number of early apoptotic cells from 6.52 to $15.65 \%$ in a dose-dependent manner. The number of late apoptotic cells also increased from $1.23 \%$ in the untreated control group to $20.51 \%$ in the group

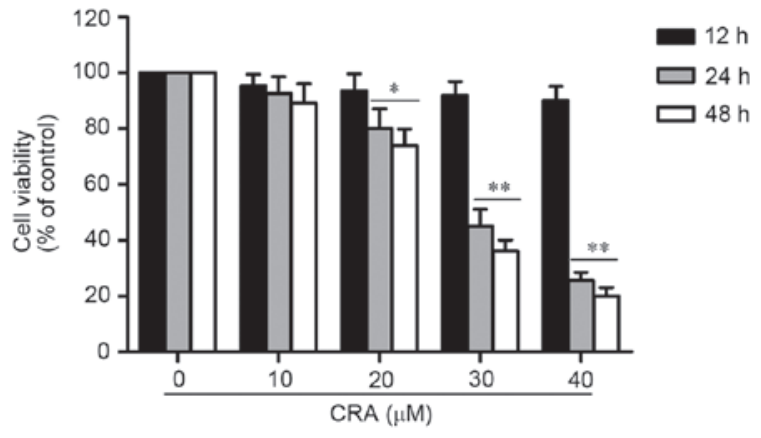

Figure 1. In vitro treatment of osteosarcoma cells with CRA inhibits the cell viability in a dose- and time-dependent manner. MG-63 cells were treated with different doses of CRA, and the cell viability was determined using the 3-(4,5-dimethyl-2-yl)-2,5-diphenyl tetrazolium bromide assay at 12, 24 and $48 \mathrm{~h}$. Cell viability following treatment with CRA was expressed in terms of percentage of control cells not treated with CRA and was presented as the mean \pm standard deviation of three experiments in triplicate. ${ }^{*} \mathrm{P}<0.05$ vs control, ${ }^{* *} \mathrm{P}<0.01$ vs. control. CRA, corosolic acid.
$\mathbf{A}$

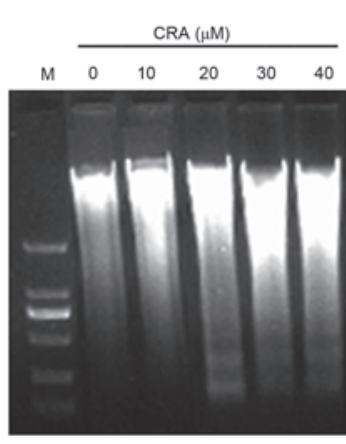

C

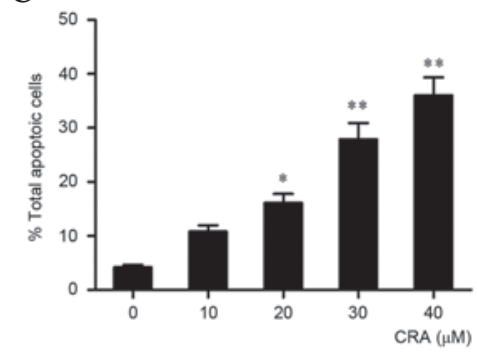

B

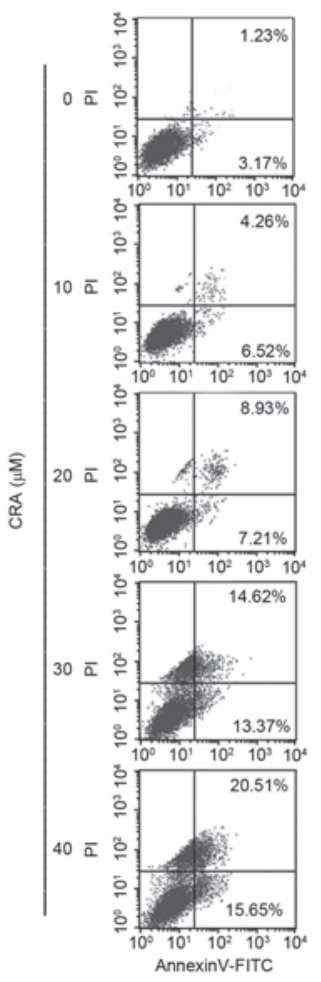

Figure 2. CRA induces apoptosis of osteosarcoma cells in a dose-dependent manner. MG-63 cells were treated with varying doses of CRA for $24 \mathrm{~h}$ and then harvested. (A) A representative ladder of DNA fragments was observed by agarose gel electrophoresis. (B) The cells were double stained using annexin V-FITC and PI, and then the stained cells were analyzed by flow cytometry. The lower right quadrant of the histograms indicated the percentage of early apoptotic cells, while the upper right quadrant indicated the percentage of late apoptotic cells. (C) CRA treatment resulted in a significant reduction in the percentage of total apoptotic cells. Results are expressed as the mean \pm standard deviation of three experiments in triplicate. ${ }^{*} \mathrm{P}<0.05$ vs. control, ${ }^{* *} \mathrm{P}<0.01$ vs. control. CRA, corosolic acid; M, marker; PI, propidium iodide; FITC, fluorescein isothiocyanate.

treated with the highest CRA concentration $(40 \mu \mathrm{M})$. The total percentage of apoptotic cells is summarized in Fig. 2C, and the results indicated that $\mathrm{CRA}$ treatment resulted in a significant increase in the apoptosis of MG-63 cells $(\mathrm{P}=0.001)$. 
A

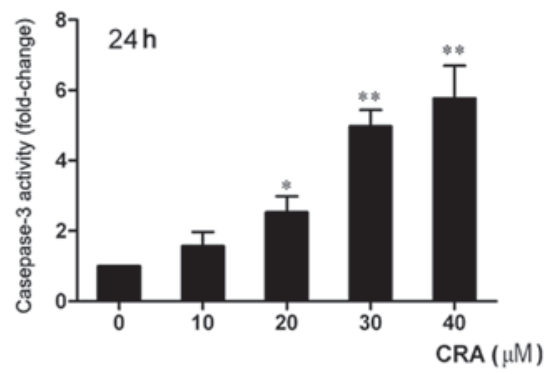

$\mathbf{C}$

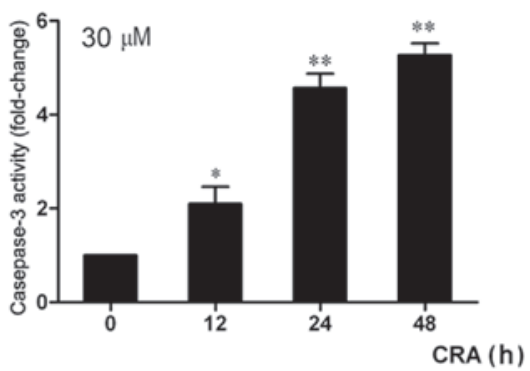

B

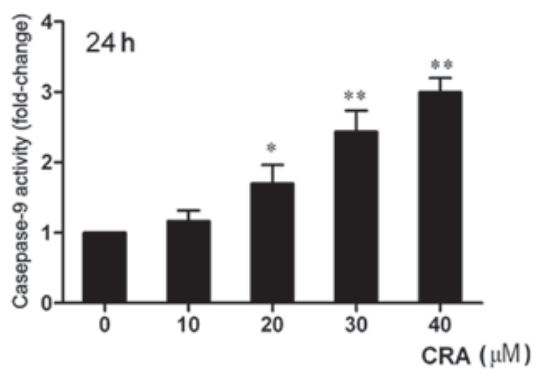

D

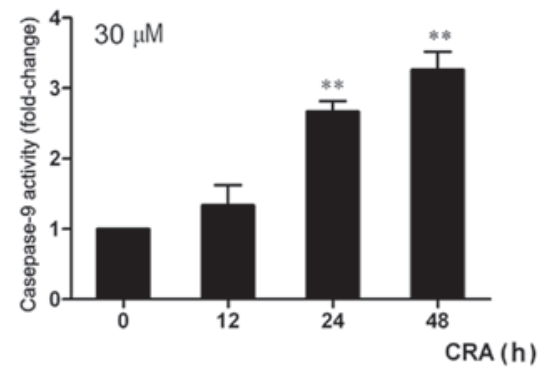

Figure 3. CRA enhances the activity of caspase-3 and -9 in osteosarcoma cells. MG-63 cells were treated with the indicated concentrations of CRA for $24 \mathrm{~h}$ and then harvested. (A) Caspase-3 and (B) caspase-9 activities in MG-63 cells were measured using a colorimetric protein assay. MG-63 cells were treated with $30 \mu \mathrm{M}$ CRA, and the activities of (C) caspase-3 and (D) caspase-9 were detected at 12, 24 and $48 \mathrm{~h}$. Results are presented as the mean \pm standard deviation from three independent experiments. ${ }^{*} \mathrm{P}<0.05$ vs. control, ${ }^{* *} \mathrm{P}<0.01$ vs. control. CRA, corosolic acid.

A

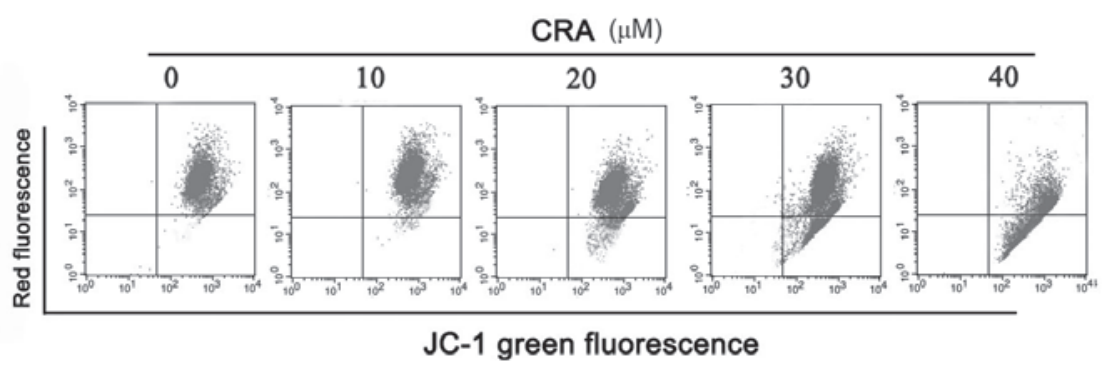

$\mathbf{B}$

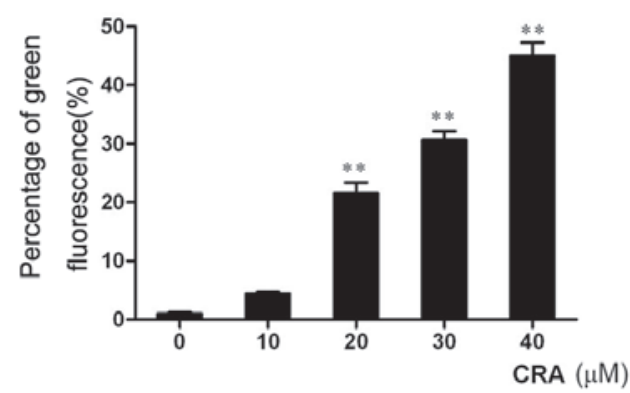

Figure 4. CRA induces the loss of mitochondrial membrane potential in osteosarcoma cells. (A) MG-63 cells were treated with different concentrations of CRA for $24 \mathrm{~h}$ and then harvested. The cells were stained with JC-1 dye and measured by flow cytometry, and representative scatterplots are shown. (B) Treatment with CRA resulted in a significant loss in mitochondrial membrane potential in MG-63 cells. Results are presented as the mean \pm standard deviation from three independent experiments. ${ }^{* *} \mathrm{P}<0.01$ vs. control. CRA, corosolic acid; JC-1, 5,5',6,6'-tetrachloro-1,1',3,3'-tetraethylbenzimidazolcarbocyanine iodide.

CRA treatment activates the caspase-3 and -9 activities of osteosarcoma cells. It is well known that the caspase pathway is important in apoptosis (30). To examine whether the apoptosis of osteosarcoma cells induced by CRA was associated with caspase protein activation, the activities of caspase- 3 and caspase- 9 were detected using a colorimetric method. The results revealed that the treatment of
MG-63 cells with the indicated concentrations of CRA for $24 \mathrm{~h}$ resulted in a significant increase in caspase- 3 activity in a dose-dependent manner (Fig. 3A), and the activity of caspase-9 in MG-63 cells treated with CRA was also significantly increased compared with that in the untreated cells (Fig. 3B, $\mathrm{P}<0.001$ ). In addition, it was also observed a time-dependent increase in the activities of caspase-3 and -9 


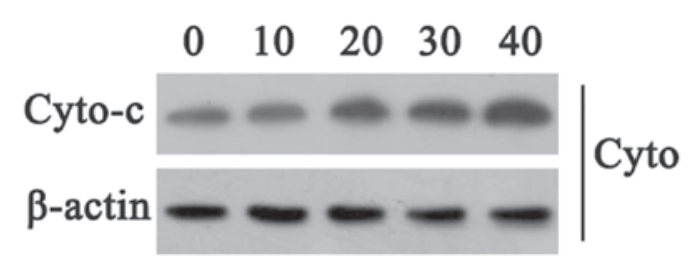

C

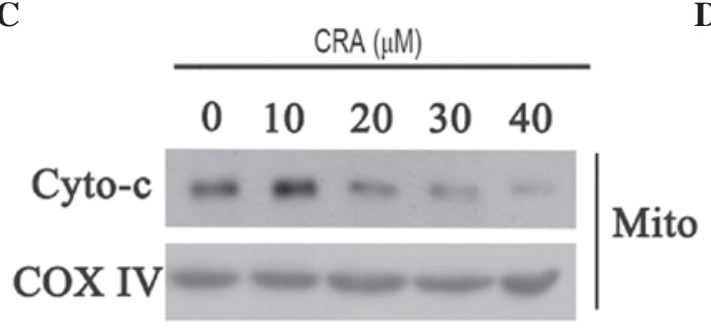

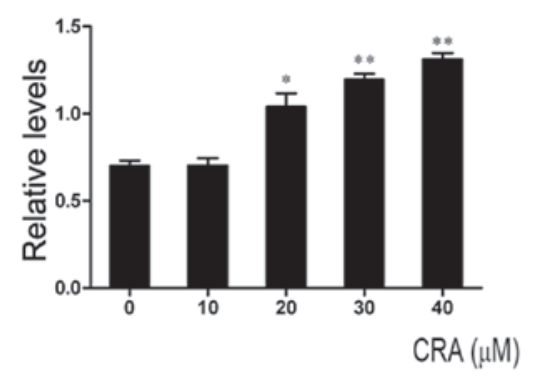

D

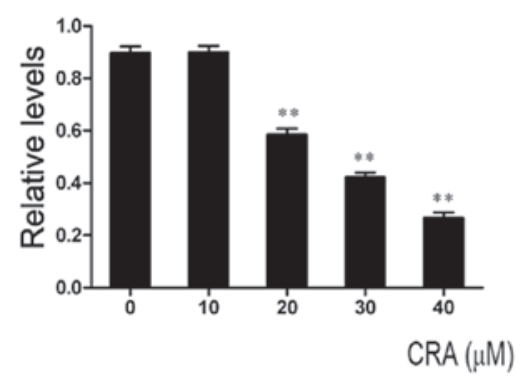

Figure 5. CRA induces cytochrome $c$ release from mitochondria. Cells were treated with varying concentrations of CRA for $24 \mathrm{~h}$ and then harvested. (A) The expression level of cytochrome $c$ in the cytoplasm was determined by western blotting, and representative blots are shown. (B) CRA treatment resulted in a significant increase in the relative expression levels of cytochrome $c$ in the cytoplasm. (C) The expression levels of cytochrome $\underline{c}$ in mitochondria were determined by western blotting, and representative blots are shown. (D) CRA treatment resulted in a significant decrease in the relative expression levels of cytochrome $c$ in mitochondria. $\beta$-actin and COX IV were used as internal controls for the mitochondrial and cytoplasmic fractions, respectively. Results are expressed as the mean \pm standard deviation of three experiments in triplicate. ${ }^{*} \mathrm{P}<0.05$ vs. control, ${ }^{* *} \mathrm{P}<0.01$ vs. control. CRA, corosolic acid; COX IV, complex IV; Cyto, cytosol; Mito, mitochondria; Cyto-c, cytochrome $c$.

A

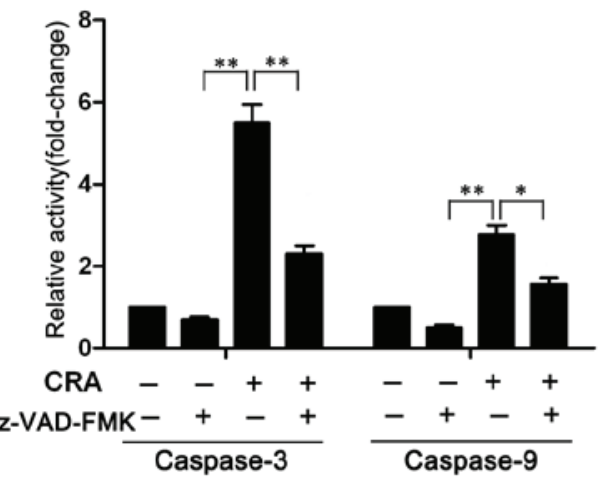

B

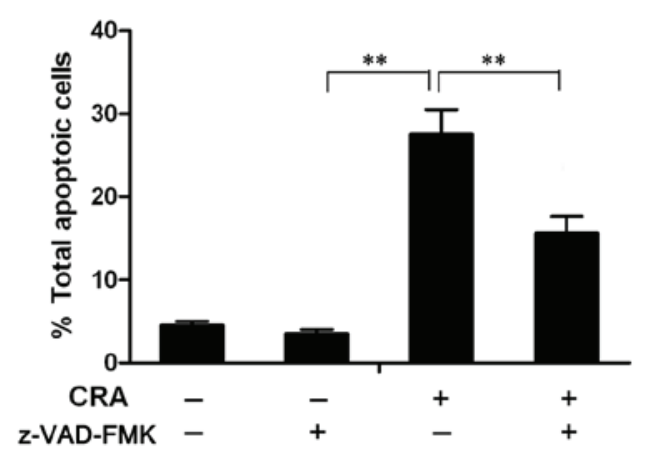

Figure 6. Caspase inhibition prevents CRA-induced apoptosis in MG-63 cells. Cells were incubated in the presence or absence of z-VAD-FMK for 1 h before being exposed to CRA $(30 \mu \mathrm{M})$. (A) After $24 \mathrm{~h}$ of incubation with CRA, caspase-3 and -9 activities were measured. (B) The percentage of apoptotic cells was detected by flow cytometry using annexin V/propidium iodide staining. The results were expressed as the mean \pm standard deviation of triplicate samples. ${ }^{*} \mathrm{P}<0.05$ vs. control, ${ }^{* *} \mathrm{P}<0.01$ vs. control. CRA, corosolic acid.

in MG-63 cells following treatment with CRA. The activities of caspase-3 and caspase- 9 increased by $\sim 2.1$ - and 1.3 -fold after $12 \mathrm{~h}$, by $4.1-$ and 2.8 -fold after $24 \mathrm{~h}$, and by 5.2 - and 3.3 -fold after $48 \mathrm{~h}$ of treatment (Fig. 3C and D). These results indicated that the apoptosis of osteosarcoma cells induced by CRA involved caspase pathway activation.

CRA induces loss of mitochondrial membrane potential. Loss of mitochondrial membrane potential has been associated with the initiation and activation of the apoptotic process in cells (31), and the variations observed for caspase- 3 and caspase- 9 activities prompted us to research a potential loss in mitochondrial membrane potential. For that purpose, a cationic lipophilic dye, JC-1, was used, which accumulates within the mitochondria in a potential-dependent manner, to determine the integrity of the mitochondrial membrane. After CRA treatment for $24 \mathrm{~h}$, MG-63 cells were harvested and incubated with JC-1 dye, and the fluorescence emission was analyzed by flow cytometry (Fig. 4A). The results revealed that CRA treatment of MG-63 cells resulted in a significant increase in the number of green fluorescence-positive cells $(\mathrm{P}<0.001$, Fig. 4B), as shown in the LR quadrant of the FACS histogram, suggesting that CRA could induce osteosarcoma cells to lose mitochondrial membrane potential. Collectively, these studies suggest that CRA treatment induces the apoptosis of osteosarcoma cells through disruption of their mitochondrial membrane potential. 
CRA induces cytochrome c release from mitochondria. Mitochondria are important in the apoptosis triggered by exogenous chemical agents (32). The disruption of the mitochondrial membrane results in the release of cytochrome $c$ into the cytosol (33). In the cytosol, cytochrome $c$ binds to apoptotic protease activating factor 1 (Apaf-1), allowing the recruitment of caspase- 9 and the formation of an apoptosome complex, resulting in caspase-3 activation and execution of cell death (25). To examine whether the apoptosis induced by CRA involved the release of mitochondrial cytochrome $c$, the levels of cytochrome $c$ in the cytoplasm and mitochondria were detected using western blotting. As shown in Fig. 5, treatment of MG-63 cells with CRA resulted in a gradual increase in cytochrome $c$ levels in the cytoplasm (Fig. 5A) and a dose-dependent decrease in cytochrome $c$ levels in the mitochondria (Fig. 5C). The relative levels of cytochrome $c$ in the cytoplasm and mitochondria were further calculated through normalization with $\beta$-actin and COX IV levels (Fig. 5B and D). The results indicated that CRA treatment provoked the release of cytochrome $c$ from the mitochondria to the cytoplasm, further confirming the above observations that CRA resulted in the loss of mitochondrial membrane potential.

Inhibition of caspase activity attenuates the apoptosis induced by $C R A$. To confirm whether CRA-induced apoptosis involved caspase cascade activation, MG-63 cells were pretreated with $100 \mu \mathrm{M}$ of z-VAD-FMK (Sigma-Aldrich; Merck Millipore), a general caspase inhibitor (34), for $1 \mathrm{~h}$, prior to be treated with CRA. The colorimetric assay revealed that the increased activity of caspase-3 and -9 induced by CRA was significantly diminished in the presence of z-VAD-FMK (Fig. 6A), suggesting that z-VAD-FMK indeed blocked the activity of caspase-3 and -9. Further analysis of apoptosis demonstrated that treatment of cells with z-VAD-FMK markedly attenuated the CRA-induced apoptosis. As shown in Fig. 6B, apoptosis was observed in $\sim 28.5 \%$ of the cells at $24 \mathrm{~h}$ following treatment with CRA in the absence of z-VAD-FMK, but only in $17.3 \%$ of the cells in the presence of z-VAD-FMK. These results clearly indicated that CRA-induced apoptosis is associated with caspase activation.

\section{Discussion}

Human osteosarcoma, a primary malignant bone tumor, is most prevalent in adolescence (35). Survival rates of osteosarcoma patients have not improved significantly in the last 25 years (36). Aiming to increase this survival rate, numerous studies have been carried out (37). Recently, several bioactive components from plant origin have been reported to offer promising options for the development of effective strategies for the therapy of cancers (33). CRA, a natural compound derived from apple pomace, has recently been shown to have anticancer activity $(1,38,39)$. To understand the effects of CRA on osteosarcoma, the effects of CRA on the osteosarcoma cell line MG-63 were evaluated in vitro in the present study.

The treatment of MG-63 cells with different concentrations of CRA resulted in a significant decrease in cell viability in a dose- and time-dependent manner. These data suggested that CRA could inhibit the proliferation of osteosarcoma cells. It is known that apoptosis plays an essential role in the development and maintenance of tissue homeostasis through eliminating unwanted or damaged cells (40), and the aberrant suppression of apoptosis is frequently associated with tumorigenesis $(41,42)$. For this reason, the induction of apoptotic cell death is an effective strategy to inhibit cancer growth. To determine whether CRA could induce the apoptotic cell death of osteosarcoma cells, the DNA from MG-63 cells treated with CRA was extracted and subjected to a DNA ladder assay. An obvious DNA ladder, which is a typical characteristic of apoptosis (28), was observed in the cells treated with CRA, but not in the untreated cells, suggesting that CRA was likely to induce the apoptotic cell death of MG-63 cells. To further confirm these results, through double staining with annexin $\mathrm{V}$ and PI, the percentage of apoptotic cells was quantitatively analyzed by flow cytometry. The results also demonstrated that CRA treatment led to a dose-dependent increase in the apoptosis of MG-63 cells. Collectively, these results suggested that CRA could induce the apoptosis of osteosarcoma cells, and that the induction of apoptosis by CRA is likely to be an important mechanism of growth inhibition in MG-63 cells.

To the best of our knowledge, the induction of apoptosis is associated with two major different activation pathways: The intrinsic pathway and the extrinsic pathway (43). The intrinsic pathway involves the loss of mitochondrial membrane potential and the release of cytochrome $c$ from the mitochondria to the cytosol $(44,45)$. The cytosolic cytochrome $c$ binds to Apaf-1 and then recruits pro-caspase- 9 , forming an apoptosome complex, which finally results in the activation of caspase-3, one of the key mediators of apoptosis, and the execution of cell death (46). The extrinsic pathway is initiated with death receptor ligation or Fas/Fas ligand interaction, resulting in the subsequent recruitment of Fas-associated death domain protein and the execution of apoptosis (47). Therefore, to clearly understand the exact mechanism of the apoptotic effect of CRA on osteosarcoma cells, the activity of caspase proteins and the integrity of the mitochondrial membrane were examined. In the present study, it was observed that treatment of MG-63 cells with CRA resulted in a significant increase in the activity of caspase- 3 and -9 and in a loss in mitochondrial membrane potential. These results suggested that the apoptosis of MG-63 cells induced by CRA was likely to involve the mitochondrial apoptotic pathway. Consistent with this notion, further investigation revealed that the levels of cytochrome $c$ in the cytoplasm of MG-63 cells treated with CRA were significantly increased compared with those in the untreated cells. On the contrary, the cytochrome $c$ levels in the mitochondria were significantly decreased compared with those in the untreated cells, which suggested that the treatment with CRA caused the cytochrome $c$ release from the mitochondria to the cytoplasm, and that the subsequent caspase cascade activation was likely to be the executive mechanism involved in CRA-mediated apoptosis.

Notably, it was also observed that the CRA-mediated increase in activity of caspase- 3 and -9 was abrogated when the general caspase inhibitor z-VAD-FMK was employed. In addition, the apoptosis of MG-63 cells induced by CRA was also significantly inhibited, suggesting that the activation of the mitochondria-mediated intrinsic death signaling pathway was completely blocked by z-VAD-FMK. These findings provide evidence that the apoptosis induced by CRA in MG-63 cells 
is mediated by the mitochondrial pathway. Our observations regarding the caspase cascade-mediated apoptosis-inducing properties of CRA were in agreement with those from previous studies $(1,34)$.

Overall, our results demonstrated that CRA could induce the apoptosis of osteosarcoma cells, and that CRA triggered the apoptosis of osteosarcoma cells via loss of mitochondrial membrane potential, release of cytochrome $c$ and activation of the caspase cascade, suggesting that the apoptosis induced by CRA was mediated by the mitochondrial pathway. The outcome of the present study indicated that CRA is a potential bioactive phytochemical for chemotherapy of osteosarcoma. However, further studies are required to determine the safety and efficacy of CRA in vivo.

\section{Acknowledgements}

The present study was supported by a grant from the Department of Healthcare, General Logistics (Beijing, China; grant number BWS 11J003).

\section{References}

1. Nho KJ, Chun JM and Kim HK: Corosolic acid induces apoptotic cell death in human lung adenocarcinoma A549 cells in vitro. Food Chem Toxicol 56: 8-17, 2013.

2. Li B, Meng X, Zhu L, Jiao X and Zhang J: Application of high-speed counter-current chromatography for isolation of triterpenes from Schisandra Chinensis (Turcz.) Baill and induction apoptosis mechanism of HSC-T6. Biomed Mater Eng 24 969-977, 2014.

3. Miura T, Takagi S and Ishida T: Management of diabetes and its complications with Banaba (Lagerstroemia speciosa L.) and corosolic acid. Evid Based Complement Alternat Med 2012: 871495, 2012.

4. Caligiani A, Malavasi G, Palla G, Marseglia A, Tognolini M and Bruni R: A simple GC-MS method for the screening of betulinic, corosolic, maslinic, oleanolic and ursolic acid contents in commercial botanicals used as food supplement ingredients. Food Chem 136: 735-741, 2013.

5. Zong W and Zhao G: Corosolic acid isolation from the leaves of Eriobotrta japonica showing the effects on carbohydrate metabolism and differentiation of 3T3-L1 adipocytes. Asia Pac J Clin Nutr 16 (Suppl 1): 346-352, 2007

6. Yin MC, Lin MC, Mong MC and Lin CY: Bioavailability, distribution, and antioxidative effects of selected triterpenes in mice. J Agric Food Chem 60: 7697-7701, 2012.

7. Chen H, Yang J, Zhang Q, Chen LH and Wang Q: Corosolic acid ameliorates atherosclerosis in apolipoprotein E-deficient mice by regulating the nuclear factor-kB signaling pathway and inhibiting monocyte chemoattractant protein-1 expression. Circ J 76: 995-1003, 2012.

8. Takagi S, Miura T, Ishihara E, Ishida T and Chinzei Y: Effect of corosolic acid on dietary hypercholesterolemia and hepatic steatosis in KK-Ay diabetic mice. Biomed Res 31: 213-218, 2010.

9. Klein G, Kim J, Himmeldirk K, Cao Y and Chen X: Antidiabetes and Anti-obesity Activity of Lagerstroemia speciosa. Evid Based Complement Alternat Med 4: 401-407, 2007.

10. Fujiwara Y, Komohara Y, Ikeda T and Takeya M: Corosolic acid inhibits glioblastoma cell proliferation by suppressing the activation of signal transducer and activator of transcription-3 and nuclear factor-kappa B in tumor cells and tumor-associated macrophages. Cancer Sci 102: 206-211, 2011.

11. Ahn KS, Hahm MS, Park EJ, Lee HK and Kim IH: Corosolic acid isolated from the fruit of Crataegus pinnatifida var. psilosa is a protein kinase $\mathrm{C}$ inhibitor as well as a cytotoxic agent. Planta Med 64: 468-470, 1998.

12. Lee MS, Cha EY, Thuong PT, Kim JY, Ahn MS and Sul JY: Down-regulation of human epidermal growth factor receptor $2 /$ neu oncogene by corosolic acid induces cell cycle arrest and apoptosis in NCI-N87 human gastric cancer cells. Biol Pharm Bull 33: 931-937, 2010.
13. Gatta G, Capocaccia R, Stiller C, Kaatsch P, Berrino F and Terenziani M; EUROCARE Working Group: Childhood cancer survival trends in Europe: A EUROCARE Working Group study. J Clin Oncol 23: 3742-3751, 2005.

14. Sulzbacher I, Birner P, Trieb K, Pichlbauer E and Lang S: The expression of bone morphogenetic proteins in osteosarcoma and its relevance as a prognostic parameter. J Clin Pathol 55: 381-385, 2002.

15. Federman N, Bernthal N, Eilber FC and Tap WD: The multidisciplinary management of osteosarcoma. Curr Treat Options Oncol 10: 82-93, 2009.

16. Lewis IJ, Nooij MA, Whelan J, Sydes MR, Grimer R, Hogendoorn PC, Memon MA, Weeden S, Uscinska BM, van Glabbeke $\mathrm{M}$, et al: Improvement in histologic response but not survival in osteosarcoma patients treated with intensified chemotherapy: A randomized phase III trial of the European Osteosarcoma Intergroup. J Natl Cancer Inst 99: 112-128, 2007.

17. Buddingh EP, Anninga JK, Versteegh MI, Taminiau AH, Egeler RM, van Rijswijk CS, Hogendoorn PC, Lankester AC and Gelderblom H: Prognostic factors in pulmonary metastasized high-grade osteosarcoma. Pediatr Blood Cancer 54: 216-221, 2010.

18. Fischer U and Schulze-Osthoff K: New approaches and therapeutics targeting apoptosis in disease. Pharmacol Rev 57: 187-215, 2005.

19. Cotter TG: Apoptosis and cancer: The genesis of a research field. Nat Rev Cancer 9: 501-507, 2009.

20. Cohen Z, Maimon Y, Yoeli-Lerner M, Yang P, Samuels N and Berger R: Selective anticancer effects and protection from chemotherapy by the botanical compound LCS101: Implications for cancer treatment. Int J Oncol 46: 308-316, 2015.

21. Lowe SW and Lin AW: Apoptosis in cancer. Carcinogenesis 21: 485-495, 2000

22. Roy AM, Baliga MS and Katiyar SK: Epigallocatechin-3-gallate induces apoptosis in estrogen receptor-negative human breast carcinoma cells via modulation in protein expression of p53 and Bax and caspase-3 activation. Mol Cancer Ther 4: 81-90, 2005.

23. Ariffin SH, Yeen WW, Abidin IZ, Abdul Wahab RM, Ariffin ZZ and Senafi S: Cytotoxicity effect of degraded and undegraded kappa and iota carrageenan in human intestine and liver cell lines. BMC Complement Altern Med 14: 508, 2014.

24. Mantena SK, Sharma SD and Katiyar SK: Berberine inhibits growth, induces G1 arrest and apoptosis in human epidermoid carcinoma A431 cells by regulating Cdki-Cdk-cyclin cascade, disruption of mitochondrial membrane potential and cleavage of caspase 3 and PARP. Carcinogenesis 27: 2018-2027, 2006.

25. Singh T, Sharma SD and Katiyar SK: Grape proanthocyanidins induce apoptosis by loss of mitochondrial membrane potential of human non-small cell lung cancer cells in vitro and in vivo. PLoS One 6: e27444 2011.

26. Wang F, Franco R, Skotak M, Hu G and Chandra N: Mechanical stretch exacerbates the cell death in SH-SY5Y cells exposed to paraquat: Mitochondrial dysfunction and oxidative stress. Neurotoxicology 41: 54-63, 2014

27. Zhang Y, Li B, Ji ZZ and Zheng PS: Notch1 regulates the growth of human colon cancers. Cancer 116: 5207-5218, 2010.

28. Song TH, Yang JY, Jeong IK, Park JS, Jee YK, Kim YS and Lee KY: Paraquat-induced apoptotic cell death in lung epithelial cells. Tuberc Respir Dis 61: 366-373, 2006.

29. Zhou J, Li P, Xue X, He S, Kuang Y, Zhao H, Chen S, Zhi Q and Guo X: Salinomycin induces apoptosis in cisplatin-resistant colorectal cancer cells by accumulation of reactive oxygen species. Toxicol Lett 222: 139-145, 2013.

30. Philchenkov A: Caspases: Potential targets for regulating cell death. J Cell Mol Med 8: 432-444, 2004.

31. Reed JC: Regulation of apoptosis by bcl-2 family proteins and its role in cancer and chemoresistance. Curr Opin Oncol 7: 541-546, 1995.

32. Xiao X, Chen L, Ouyang Y, Zhu W, Qiu P, Su X, Dou Y, Tang L, Yan M, Zhang H, et al: Pregnenolone, a cholesterol metabolite, induces glioma cell apoptosis via activating extrinsic and intrinsic apoptotic pathways. Oncol Lett 8: 645-650, 2014.

33. Chen Q, Liu XF and Zheng PS: Grape seed proanthocyanidins (GSPs) inhibit the growth of cervical cancer by inducing apoptosis mediated by the mitochondrial pathway. PLoS One 9: e107045, 2014.

34. Xu Y, Ge R, Du J, Xin H, Yi T, Sheng J, Wang Y and Ling C: Corosolic acid induces apoptosis through mitochondrial pathway and caspase activation in human cervix adenocarcinoma HeLa cells. Cancer Lett 284: 229-237, 2009. 
35. Shi Z1, Huang X, Liu B, Tao H, Cai Y and Tang R: Biological response of osteosarcoma cells to size-controlled nanostructured hydroxyapatite. J Biomater Appl 25: 19-37, 2010.

36. Kuijjer ML, Namløs HM, Hauben EI, Machado I, Kresse SH, Serra M, Llombart-Bosch A, Hogendoorn PC, Meza-Zepeda LA, Myklebost $\mathrm{O}$ and Cleton-Jansen AM: mRNA expression profiles of primary high-grade central osteosarcoma are preserved in cell lines and xenografts. BMC Med Genomics 4: 66, 2011.

37. Biao LU: Correlation between ErbB2 expression and survival rates of osteosarcoma patients. Medical Journal of Wuhan University 2: 273-276, 2014.

38. Sung B, Kang YJ, Kim DH, Hwang SY, Lee Y, Kim M, Yoon JH, Kim CM, Chung HY, Kim ND: Corosolic acid induces apoptotic cell death in HCT116 human colon cancer cells through a caspase-dependent pathway. Int J Mol Med 33: 943-949, 2014.

39. Fujiwara Y, Takaishi K, Nakao J,Ikeda T, Katabuchi H, Takeya M and Komohara Y: Corosolic acid enhances the antitumor effects of chemotherapy on epithelial ovarian cancer by inhibiting signal transducer and activator of transcription 3 signaling. Oncol Lett 6: 1619-1623, 2013

40. Thompson CB: Apoptosis in the pathogenesis and treatment of disease. Science 267: 1456-1462, 1995.

41. Correa P and Miller MJ: Carcinogenesis, apoptosis and cell proliferation. Br Med Bull 54: 151-162, 1998.
42. Ambrosini G, Adida C and Altieri DC: A novel anti-apoptosis gene, survivin, expressed in cancer and lymphoma. Nat Med 3: 917-921, 1997.

43. Zou WW, Xiao HP, Gu MN, Liu KX and Liu ZQ: Propofol induces rat embryonic neural stem cell apoptosis by activating both extrinsic and intrinsic pathways. Mol Med Rep 7: 1123-1128, 2013.

44. Chipuk JE, Kuwana T, Bouchier-Hayes L, Droin NM, Newmeyer DD, Schuler M and Green DR: Direct activation of Bax by $\mathrm{p} 53$ mediates mitochondrial membrane permeabilization and apoptosis. Science 303: 1010-1014, 2004.

45. Tan J, Zhuang L, Leong HS, Iyer NG, Liu ET and Yu Q: Pharmacologic modulation of glycogen synthase kinase-3beta promotes p53-dependent apoptosis through a direct Bax-mediated mitochondrial pathway in colorectal cancer cells. Cancer Res 65: 9012-9020, 2005

46. Kluck RM, Bossy-Wetzel E, Green DR and Newmeyer DD: The release of cytochrome $\mathrm{c}$ from mitochondria: A primary site for Bcl-2 regulation of apoptosis. Science 275: 1132-1136, 1997.

47. Kischkel FC, Hellbardt S, Behrmann I, Germer M, Pawlita M, Krammer PH and Peter ME: Cytotoxicity-dependent APO-1 (Fas/CD95)-associated proteins form a death-inducing signaling complex (DISC) with the receptor. EMBO J 14: 5579-5588, 1995 . 